\section{EMBRYRIDDLE \\ Aeronautical University}

SCHOLARLY COMMONS
International Journal of Aviation, Aeronautics, and Aerospace

Volume 6 | Issue 5

Article 1

2019

\title{
A new model for lifting condensation levels estimation
}

Nihad E. Daidzic Ph.D., Sc.D.

AAR Aerospace Consulting, LLC, aaraerospace@cs.com

Follow this and additional works at: https://commons.erau.edu/ijaaa

Part of the Atmospheric Sciences Commons, Aviation Commons, and the Meteorology Commons

\section{Scholarly Commons Citation}

Daidzic, N. E. (2019). A new model for lifting condensation levels estimation. International Journal of Aviation, Aeronautics, and Aerospace, 6(5). https://doi.org/10.15394/ijaaa.2019.1341

This Article is brought to you for free and open access by the Journals at Scholarly Commons. It has been accepted for inclusion in International Journal of Aviation, Aeronautics, and Aerospace by an authorized administrator of Scholarly Commons. For more information, please contact commons@erau.edu. 


\section{Introduction}

An important concept in meteorology, cloud physics, weather, and atmospheric sciences is the Lifting Condensation Level (LCL). It expresses the height above the ground (AGL) at which isentropically ascending moist (humid) air parcel reaches water-vapor saturation pressure or $\mathrm{RH}=100 \%$. This is the minimum height at which some cloud bases may be formed (e.g., cumulus clouds) as illustrated in Figure 1. Air and dew point (DP) temperatures, and to a smaller extent local atmospheric pressure, control the condensation process and the formation of clouds. Theoretically, condensation and cloud formation would start at the LCL, or practically bit higher depending on the availability of the condensation nuclei $(\mathrm{CN})$. Since LCL defines bases of cumulus clouds due to vertical air motion it also significantly affects flight operations. Normally, an ideal flat ground surface is assumed when considering air parcel lifting. However, Wetzel (1990) used a simple parcel method for prediction of cumulus onset over heterogeneous land surfaces. In addition to LCL, we may also define LDL and LFL, for which recent estimates were given by Romps (2017). While LCL (condensation) and LDL (deposition, sublimation) involve heterogeneous nucleation, LFL involves homogenous nucleation over solid phase (ice) which may involve substantial metastable super-cooling of water vapor (Romps, 2017). For more details on LCL, LDL, LFL and related processes consult Dutton (2002), Romps (2017), Rogers (1979), Saucier (1989), and Wallace and Hobbs (2006). LCL can be graphically determined from the Skew-T vs. Log-p diagrams using Normand's rule (Wallace \& Hobbs, 2006). Of aviation-weather oriented books, Bradbury (2000) provided decent analysis of the LCL phenomena and the conditions under which condensation occurs, but does not mention or evaluate LCL itself. Some other useful pilot and aviation-oriented books dealing with thermals, lifting phenomena, cumulus clouds formation, etc., are by Cosgrove (1990), Federal Aviation Administration (FAA; 2016), Jeppesen (2015), Lester (2007), Piggot (1996), and Reichmann (1993).

The first historically recorded definition and treatment of LCL and cloud formation is due to Espy (1836). The famous meteorologist of the 19th century recognized the importance of latent heat during the time when "heat" was still described through an old and defunct "caloric theory" and the now obsolete notion of "ether". McDonald (1963) and Romps (2017) provided many historical accounts and description of Espy's work and subsequent LCL estimates by other authors. In fact, Romps (2017) recently succeeded in deriving an exact formulation of LCL, LFL and LDL heights using optimized constant thermodynamic properties. The solution of the Romp's model equations is somewhat complicated and requires the understanding of Lambert's $W$ special function. More on the Lambert functions 
(Swiss polymath Johann Heinrich Lambert 1728-1777), which has many applications in theoretical and applied mathematics, science, and engineering, can be found in Corless et al. (1996) and Zwillinger (2018). It is interesting to note that coincidentally J. H. Lambert also introduced albedo into optics. Terrestrial albedo plays dominant role in energy balance of Earth. A nomenclature is provided at the end of the article.

\section{Mathematical Models of LCL}

Here, we present some known formulations and LCL estimations and then derive new model for LCL predictions. Using thermodynamic principles of moist air (Daidzic, 2019a), we also derive a nonlinear implicit equation for LCL temperature, which does not have explicit solution and must be solved numerically. We use the method of fixed-point iterations to predict LCL temperature. From LCL temperatures, we can then estimate LCL heights and pressures. Differences between the geopotential $(\mathrm{H})$ and the orthometric $(\mathrm{z})$ heights are neglected.

Based on the research and recommendations by McDonald (1963), Lawrence (2005), Romps (2017), and others, we define Espy's LCL height estimate (AGL) as:

$$
z_{L C L}=125 \cdot\left(T-T_{D P}\right)=125 \cdot D[\mathrm{~m}]
$$

Converted to MSL altitude with $z_{0}$ the elevation of the surface where DP and temperature are measured, the LCL becomes: $z_{L C L}=z_{0}+125 \cdot\left(T-T_{D P}\right)$. In terms of RH (>50\%), Lawrence (2005) proposes simple expression, which transforms into Espy's estimate Equation (1) when Lawrence's linear estimate of $\mathrm{RH}$ is used:

$$
z_{L C L}=25 \cdot(100-R H)[\mathrm{m}]
$$

Lawrence (2005) also provides improved LCL height estimates using relationships for $\mathrm{RH}$, but comparison with other models show excessively large deviations:

$$
z_{L C L}=\left(20+\frac{\theta}{5}\right) \cdot(100-R H)
$$

Estimate of LCL MSL altitude based on the initial (surface) DP depression, elevation and DALR vs DPLR difference yields: 


$$
z_{L C L}=z_{0}+\frac{T_{A I R, 0}-T_{D P, 0}}{\Gamma_{d}-\Gamma_{D P}} \approx z_{0}+\frac{D_{0}}{8} \cdot 1000 \approx z_{0}+125 \cdot D_{0}[\mathrm{~m}]=z_{0}+410 \cdot D_{0}[\mathrm{ft}]
$$

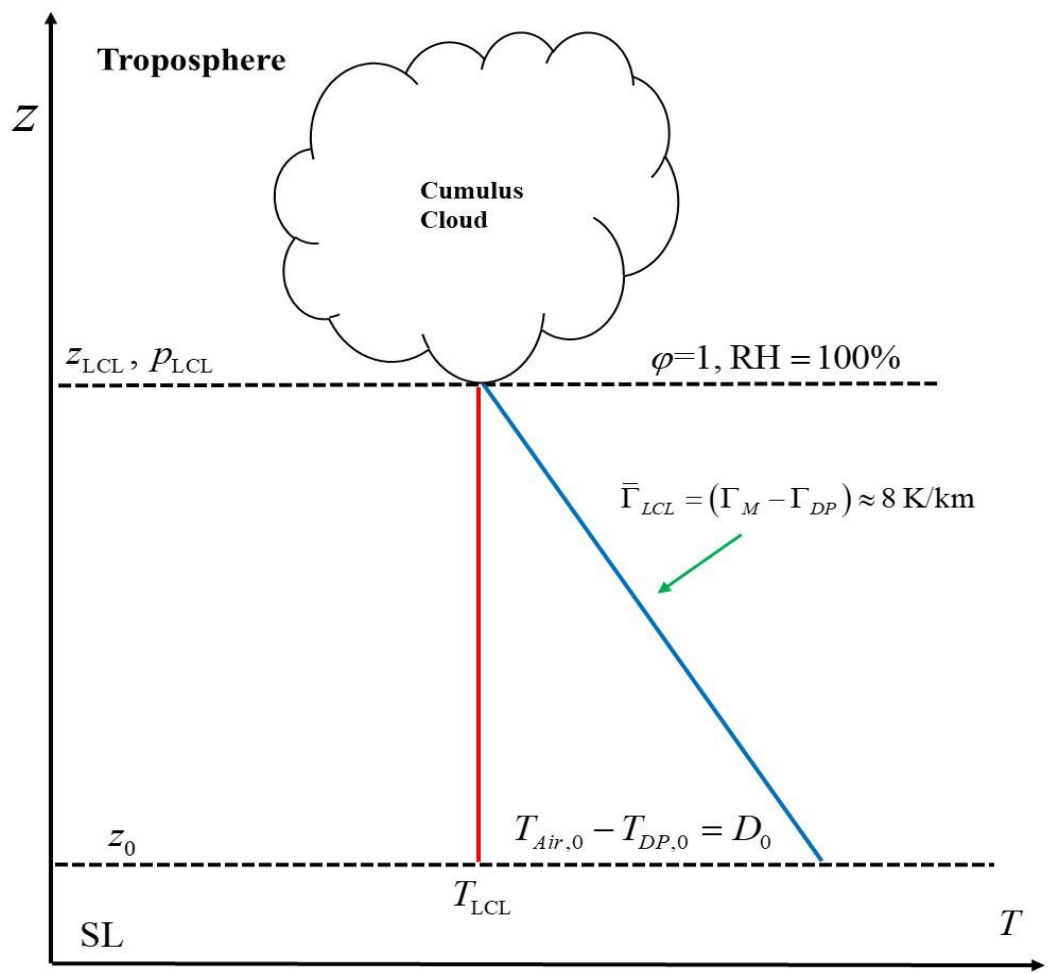

Figure 1. Graphic representation of moist air lifting and condensation onset at LCL. (Not to scale).

Notice that in the above expression, DALR is used, which neglects any dependence on the actual specific humidity of air. This yields similar result to an LCL estimate (rule-of-thumb) used in FAA and some commercial flight training references (FAA, 2016; Jeppesen, 2015) and practical aviation weather textbooks (Lester, 2007) in which DP spread is divided by 2.5 (in ${ }^{\circ} \mathrm{C}$ or ${ }^{\circ} \mathrm{K}$ ) to arrive at the AGL bases of cumulus clouds in thousands of feet:

$z_{L C L}=\frac{T_{A I R, 0}-T_{D P, 0}}{2.5} \cdot 1000=400 \cdot D_{0}[\mathrm{ft}]$

This is because the average difference between the DALR and the DPLR is about $8 \mathrm{~K} / \mathrm{km}(9.8-1.8=8.0)$ or rounded about $2.5 \mathrm{~K} / 1000 \mathrm{ft}$ (Daidzic, 2019b). If the temperature is measured in ${ }^{\circ} \mathrm{F}$, then the denominator in Equation (5) should be 4.4 
(Jeppesen, 2015; Lester, 2007) with the height expressed in 1000s ft. In the absence of additional historic information, we decided to call Equation (5), an FAA LCL estimate.

However, LCL height depends on the MALR vs DPLR difference and both are functions of specific humidity as well. Air properties are slightly changing as moist air ascends thereby increasing relative humidity. Hence, we propose an explicit equation for LCL height estimate:

$$
z_{L C L}\left(T, T_{D P}\right)=\frac{T-T_{D P}}{\Gamma_{M}-\Gamma_{D P}}=\frac{D_{0}}{\Gamma_{d}} \cdot\left[(1-0.856 \cdot \mathrm{q})-6.461 \times 10^{-4} \cdot(1-0.61 \cdot \mathrm{q}) \cdot T \cdot\left(1-\frac{D}{T}\right)^{2}\right]^{-1}
$$

Specific humidity $\mathbf{q}$ depends on the measured air temperature and DP and is not a free or independent variable. The expression for the surface specific humidity for known air temperature, DP depression, and local atmospheric pressure yields (Daidzic, 2019a):

$$
\mathrm{q}(T, D, p)=\varphi \cdot \mathrm{q}_{s}(p, T) \approx \frac{380.14}{p} \cdot \exp \left[54.015-\frac{6829.36}{T}-5.1723 \cdot \ln T-\frac{5417.12 \cdot D}{T(T-D)}\right]
$$

Hence, LCL height is a weak function of atmospheric pressure and is often ignored, such as in Espy's, FAA's, and Lawrence's estimates. In our estimates using Equation (7), the surface atmospheric pressure input is required to compute specific humidity. Subsequently, we calculate temperature at LCL from the linear relationship (for illustration see Fig. 1):

$$
T_{L C L}=T_{A i r, 0}-\left(z_{L C L}-z_{0}\right) \cdot \Gamma_{M}=T_{A i r, 0}-\left(z_{L C L}-z_{0}\right) \cdot \Gamma_{d}(1-0.856 \cdot \mathrm{q})
$$

In this method, the LCL height is first calculated explicitly from Equations (6) and (7) and then the value of $z_{L C L}$ substituted into Equation (8) for known MALR to obtain $T_{L C L}$. As shown in Equation (8), MALR is computed from DALR and the specific humidity (Daidzic, 2019) which we can find using Equation (7). Clearly, at LCL:

$$
T_{A i r}=T_{D P}=T_{W B}=T_{L C L}
$$

We will now develop an alternate method of estimating LCL parameters. First, we define RH as (Daidzic, 2019a, 2019b): 


$$
\varphi=\left(\frac{R H}{100}\right)=\frac{e(T)}{e_{s}(T)} \leq 1
$$

Taking the natural logarithm of $\mathrm{RH}$, we obtain:

$$
\ln \varphi(T)=\ln e(T)-\ln e_{s}(T)
$$

The Clausius-Clapeyron equation with an ideal-gas approximation (Daidzic, 2019a; Iribarne \& Cho, 1980; Iribarne \& Godson, 1981; Tsonis, 2007; Wallace \& Hobbs, 2006) yields:

$$
\frac{d e_{s}}{d T}=\frac{l_{v} \cdot e_{s}}{R_{v} \cdot T^{2}}
$$

Isentropic lifting of moist air at constant specific humidity can be obtained by differentiating Equation (10) resulting in:

$$
d(\ln \varphi)=\frac{\gamma_{m}}{\gamma_{m}-1} d(\ln T)-d\left(\ln e_{s}\right)=\frac{\gamma_{m}}{\gamma_{m}-1} d(\ln T)+\frac{l_{v}}{R_{v}} d\left(\frac{1}{T}\right)
$$

Here we utilized the fact that (Daidzic, 2019a):

$$
d(\ln e)=d(\ln r-\ln 0.622)+d(\ln p)
$$

At LCL, the RH is $100 \%(\varphi=1)$ and the temperature and pressure reach LCL values. After integration between surface values $(\varphi, T, p)$ and condensation limits $\left(\varphi_{L C L}=1, T_{L C L}, p_{L C L}\right)$, by neglecting small changes of some thermodynamic properties, we obtain:

$$
\int_{\varphi}^{1} d(\ln \varphi)=\frac{\gamma_{m}}{\gamma_{m}-1} \int_{T}^{T_{L C L}} d(\ln T)+\frac{l_{v}}{R_{v}} \int_{T}^{T_{L C L}} d\left(\frac{1}{T}\right)
$$

Integrating and using moist air thermodynamic relationships (Daidzic, 2019a):

$$
\varphi=\exp \left[\frac{l_{v}}{R_{v}}\left(\frac{1}{T}-\frac{1}{T_{D P}}\right)\right]
$$


we obtain an implicit nonlinear equation in $T_{L C L}$ :

$$
\frac{l_{v}}{R_{v}}\left(\frac{1}{T_{D P}}-\frac{1}{T}\right)=\frac{\gamma_{m}}{\gamma_{m}-1} \ln \left(\frac{T_{L C L}}{T}\right)+\frac{l_{v}}{R_{v}}\left(\frac{1}{T_{L C L}}-\frac{1}{T}\right)
$$

The above nonlinear equation has no explicit solution in terms of LCL temperature. To find unknown temperature at LCL we resort to using a numerical root-finding solver. Tsonis (2007) suggests numerically solving Equation (17), but does not demonstrate it. We could also use Bolton's (1980) theoretical seriesapproximation of Equation (17). While Bolton (1980) avoided solving nonlinear equation in his original work, we propose a simple numerical method of successive approximations or fixed-point iteration (Chapra \& Canale, 2006) to solve nonlinear Equation (17). Rearranging the terms in Equation (17), we obtain:

$$
\begin{aligned}
& T_{L C L}^{(n+1)}=\left[\frac{1}{T_{D P}}-A(\mathrm{q}) \cdot \ln \left(\frac{T_{L C L}^{(n)}}{T}\right)\right]^{-1} \quad A(\mathrm{q})=\left(\frac{\gamma_{m}}{\gamma_{m}-1}\right) \frac{R_{v}}{l_{v}} \approx 6.461 \times 10^{-4}(1+0.25 \cdot \mathrm{q}) \\
& T_{L C L}^{1}=T_{D P} \quad n=1,2, \ldots
\end{aligned}
$$

For the starting (initial) value for $T_{L C L}$, we chose readily available reported, measured or estimated $T_{D P}$ at the surface elevation $z_{0}$. This numerical algorithm results in moderately rapid convergence in all the cases we tested. Of course, $T_{L C L}$ is lower than the surface measured DP temperature. The convergence of Equation (18) is reasonably fast (5-6 iterations for 5 significant digits accuracy). The convergence criteria are defined for absolute difference between two subsequent iterations to be less than an arbitrary chosen small number:

$$
\left|T_{L C L}^{(i+1)}-T_{L C L}^{(i)}\right| \leq \delta \quad i=1,2,3, \ldots
$$

This simple procedure can be easily coded in any programming language (Basic, C++, Fortran, Matlab, etc.), spreadsheet program, scientific/engineering calculators, or even performed manually using hand-held portable calculators. Atmospheric air pressure at LCL follows from the wet-adiabat equation (Daidzic, 2019a; Iribarne \& Cho, 1980; Iribarne \& Godson, 1981; Tsonis, 2007; Wallace \& Hobbs, 2006):

$$
p_{L C L}=p \cdot\left(\frac{T_{L C L}}{T}\right)^{\frac{\gamma_{m}}{\gamma_{m}-1}}
$$


Bolton (1980) gives explicit series approximation for $T_{L C L}$, while Romps (2017) gives exact solution of $T_{L C L}$ in his moist air adiabatic ascent model in terms of Lambert's $W$ special functions from which then LCL height and pressure are also computed. Bolton's (1980) approximation of $T_{L C L}$ yields:

$$
T_{L C L}=\frac{1}{\frac{1}{T-55}-\frac{\ln \varphi}{2840}}+55[\mathrm{~K}]
$$

Assuming LRs are constant, we can express the LCL height in several ways:

$$
z_{L C L}-z_{0}=\frac{T_{A i r, 0}-T_{L C L}}{\Gamma_{M}}=\frac{T_{D P, 0}-T_{L C L}}{\Gamma_{D P}}=\frac{T_{A i r, 0}-T_{D P, 0}}{\left(\Gamma_{M}-\Gamma_{D P}\right)}=\frac{T_{A i r, 0}-T_{D P, 0}}{\Gamma_{L C L}}=\frac{D_{0}}{\Gamma_{L C L}}
$$

Using the first equality from Equation (22) and the expression for MALR (Daidzic, 2019b), we can express LCL height using Bolton's estimate directly as:

$$
z_{L C L}-z_{0}=\frac{1}{\Gamma_{d}}(1+0.856 \cdot \mathrm{q})\left[T-55-\left(\frac{1}{T-55}-\frac{\ln \varphi}{2840}\right)^{-1}\right] \quad \Gamma_{d}=\frac{g_{0}}{c_{p d}}
$$

The question is how sensitive or uncertain LCL height estimates are to small perturbations of influence parameters. The total differential for LCL height from the first equality above yields:

$$
\Delta z_{L C L}=\left(\frac{\partial z_{L C L}}{\partial T}\right) \Delta T+\left(\frac{\partial z_{L C L}}{\partial T_{L C L}}\right) \Delta T_{L C L}+\left(\frac{\partial z_{L C L}}{\partial \Gamma_{M}}\right) \Delta \Gamma_{M}
$$

After evaluating partial derivatives, the relative change of LCL height becomes:

$$
\frac{\Delta z_{L C L}}{z_{L C L}}=\left(\frac{T}{T-T_{L C L}}\right)_{0} \frac{\Delta T}{T}-\left(\frac{T_{L C L}}{T-T_{L C L}}\right)_{0} \frac{\Delta T_{L C L}}{T_{L C L}}-(1)_{0} \frac{\Delta \Gamma_{M}}{\Gamma_{M}}
$$

We could apply the same methodology to other equalities in Equation (22). For example, measured surface air temperature is $300 \mathrm{~K}\left(\approx 27^{\circ} \mathrm{C}\right)$, LCL temperature is $280 \mathrm{~K}\left(\approx 7^{\circ} \mathrm{C}\right)$, and MALR is $9.5 \mathrm{~K} / \mathrm{km}$. LCL height is then about $2.1 \mathrm{~km}(\approx 6,900$ $\mathrm{ft}$ ). By evaluating small linear perturbations around stationary perturbation points "0" in Equation (25), we obtain: 


$$
\frac{\Delta z_{L C L}}{z_{L C L}}=15 \cdot \frac{\Delta T}{T}-14 \cdot \frac{\Delta T_{L C L}}{T_{L C L}}-\frac{\Delta \Gamma_{M}}{\Gamma_{M}}
$$

Accordingly, a $1 \%$ increase in surface DB air temperature $\left(3{ }^{\circ} \mathrm{K}\right.$ or from 27 to $30^{\circ} \mathrm{C}$ ) will cause significant $15 \%$ increase of the LCL height (from $2.1 \mathrm{~km}$ to about $2.42 \mathrm{~km}$ ). Similar sensitivity would exist with DP temperature measurement. A $1 \%$ increase in LCL temperature $\left(2.8{ }^{\circ} \mathrm{K}\right.$ or from 7 to $\left.9.8^{\circ} \mathrm{C}\right)$ will cause $14 \%$ decrease in the LCL height (from $2.1 \mathrm{~km}$ to about $1.81 \mathrm{~km}$ ). A 1\% MALR change $(9.5 \pm 0.095 \mathrm{~K} / \mathrm{km})$ will only produce $1 \%$ change in LCL height $(2,100 \pm 21 \mathrm{~m})$. Thus, LCL height is directly very sensitive to air temperatures and inversely to LCL temperatures estimations or measurements and inversely linearly sensitive to LR changes. This represents major effect in weather forecasting. Hence, accurate measurements of air and DP temperatures are essential for accurate estimations of LCL heights. Air pressure at LCL assuming isentropic ascent of moist air until RH reaches $100 \%$ is now easily computed using the Poisson's equation given in Equation (20).

\section{Results and Discussion}

LCL height computations (solid lines) as functions of surface air temperature and for various surface DP depressions (2-15 K) as parametric curves are shown in a rather busy graph in Fig. 2. LCL height using our model is based on simultaneously solving Equations (6) and (7). In addition to our model derived here, comparison with various other models is presented. Hence, we present LCL heights computations from Lawrence's model (dashed lines), Espy's (doted lines), FAA's (dense dashed lines), and Bolton's LCL height estimate using Equation 23 (symbols). LCL heights computed from our model (Equations. 6, 7, 8, and 20) are weakly dependent on specific humidity. The effect is strongest at high air temperatures and high DPs (low DP depressions). Estimations of LCL heights typically do not carry explicit atmospheric pressure dependence as seen from the simple Espy's and FAA's estimates. However, our model does account for atmospheric pressure dependence. We performed several computations with reduced atmospheric pressures (900, 800 mbar, etc.). The LCL height difference compared to SL ISA pressure is indeed low on the order of few meters only (temperature dependent 1-4 $\mathrm{m}$ for each 100 mbar lower atmospheric pressure) depending on the actual DP depression and air temperature. Romps (2017) also emphasizes the requirement for surface air pressure input in LCL computations. At low DP depressions (high DPs), the effect of specific humidity is minimal and the LCL height is almost constant and independent of air temperature. Of various older LCL-height models used, Bolton's LCL estimate gives overall the best match overestimating LCL heights a bit at higher temperatures. Bolton's LCL height 
approximations are based on Equations. (21) for $\mathrm{T}_{\mathrm{LCL}}$ and (22) for $\mathrm{Z}_{\mathrm{LCL}}$ in constant LR atmosphere or directly solving Equation (23).

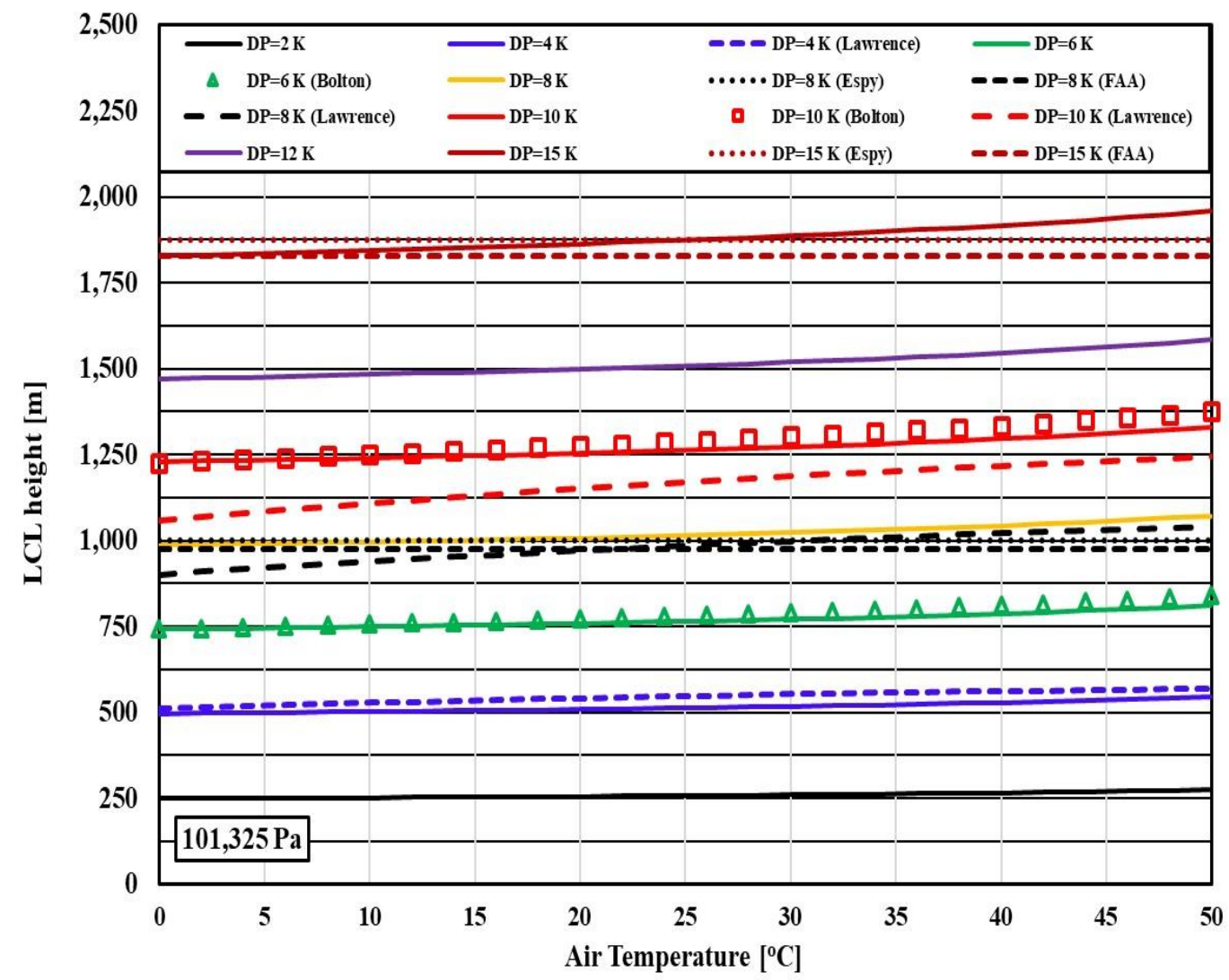

Figure 2. LCL height computations using various models.

The model derived here also correctly predicts the trend in which LCL heights decrease with increasing DP temperatures (or decreasing DP depressions) at constant air temperatures. Lawrence's LCL height estimate with RH computed using Clausius-Clapeyron phase-transition equation (Daidzic, 2019a) is only acceptable at high RHs and lower temperatures. Lawrence's LCL estimates using linear RH approximation (Lawrence, 2005) shows even larger discrepancies. It was difficult to compare numerical values from our model directly with other published models as results are normally presented graphically only. However, Romps (2017) at one point in his article provides a numerical value of LCL height of 1,435 m for an air parcel having ISA SL temperature of $300 \mathrm{~K}\left(26.85^{\circ} \mathrm{C}\right)$ and $\mathrm{RH}$ of $50 \%$. Our model delivers LCL height of $1,400.35 \mathrm{~m}$ (about $35 \mathrm{~m}$ or $115 \mathrm{ft}$ difference) at the same SL pressure, air temperature, and RH (DP is $15.76^{\circ} \mathrm{C}$ or $288.91 \mathrm{~K}$ and DP 
depression is $11.09^{\circ} \mathrm{C}$ ). Computed $\mathrm{T}_{\mathrm{LCL}}$ is $13.32^{\circ} \mathrm{C}$ and $\mathrm{p}_{\mathrm{LCL}}$ is $861.76 \mathrm{mbar}$. This is somewhat disappointing and larger difference than expected or about $2 \%$ accounting for stated maximum uncertainties in Romps' model. Espy's, FAA, and Bolton's estimates returned heights of 1,386.25, 1,352.11, and 1,430.85 $\mathrm{m}$ for same conditions respectively. Bolton's model (Bolton, 1980) came within $5 \mathrm{~m}$ (16.5 ft) of Romps', but that may have been just a coincidence.

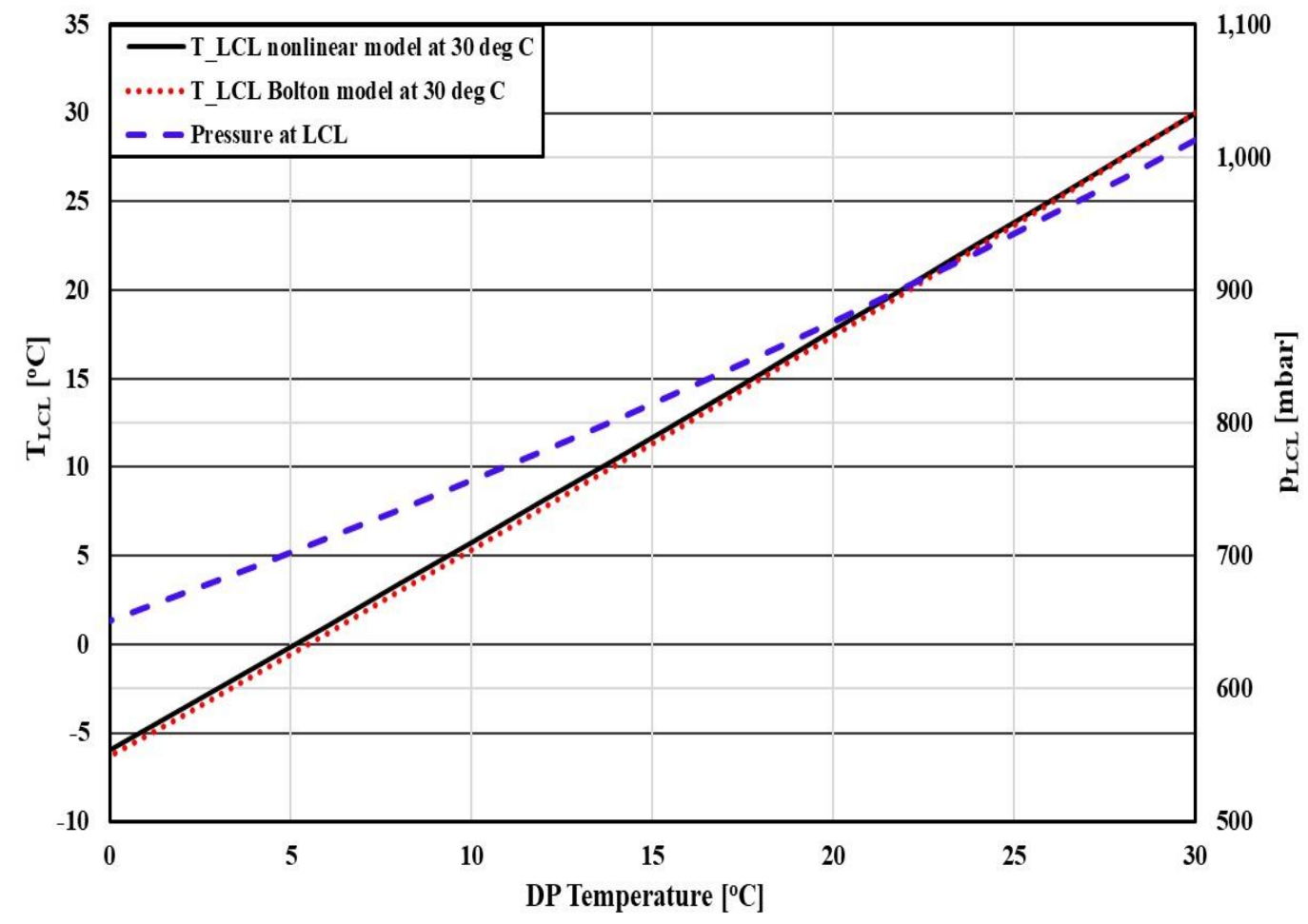

Figure 3. LCL temperature and pressure at SL ISA surface and air temperature of $30^{\circ} \mathrm{C}$.

Hence, it is not possible to make full comparison with Romp's model until all numerical values are available, which may be done in the future contribution. One of the possible, yet small, sources of discrepancy between our and Romp's model is due to using different numerical values for various thermodynamic parameters and coefficients. In addition, we used simple constant-coefficients phase transition models based on Clausius-Clapeyron equation and our theoretical water-vapor saturation model is also less accurate (assumes water-vapor is an ideal gas) then Romp's. In general, errors in our model compared to Romps' (2017) are on the same order of magnitude as Bolton's. We did not optimize thermodynamic 
parameters to minimize overall error. More effort may be spent in the future to understand all the sources of discrepancies. Nevertheless, our present model still provides decent accuracy and simplicity in the presence of many uncertainties and approximations made.

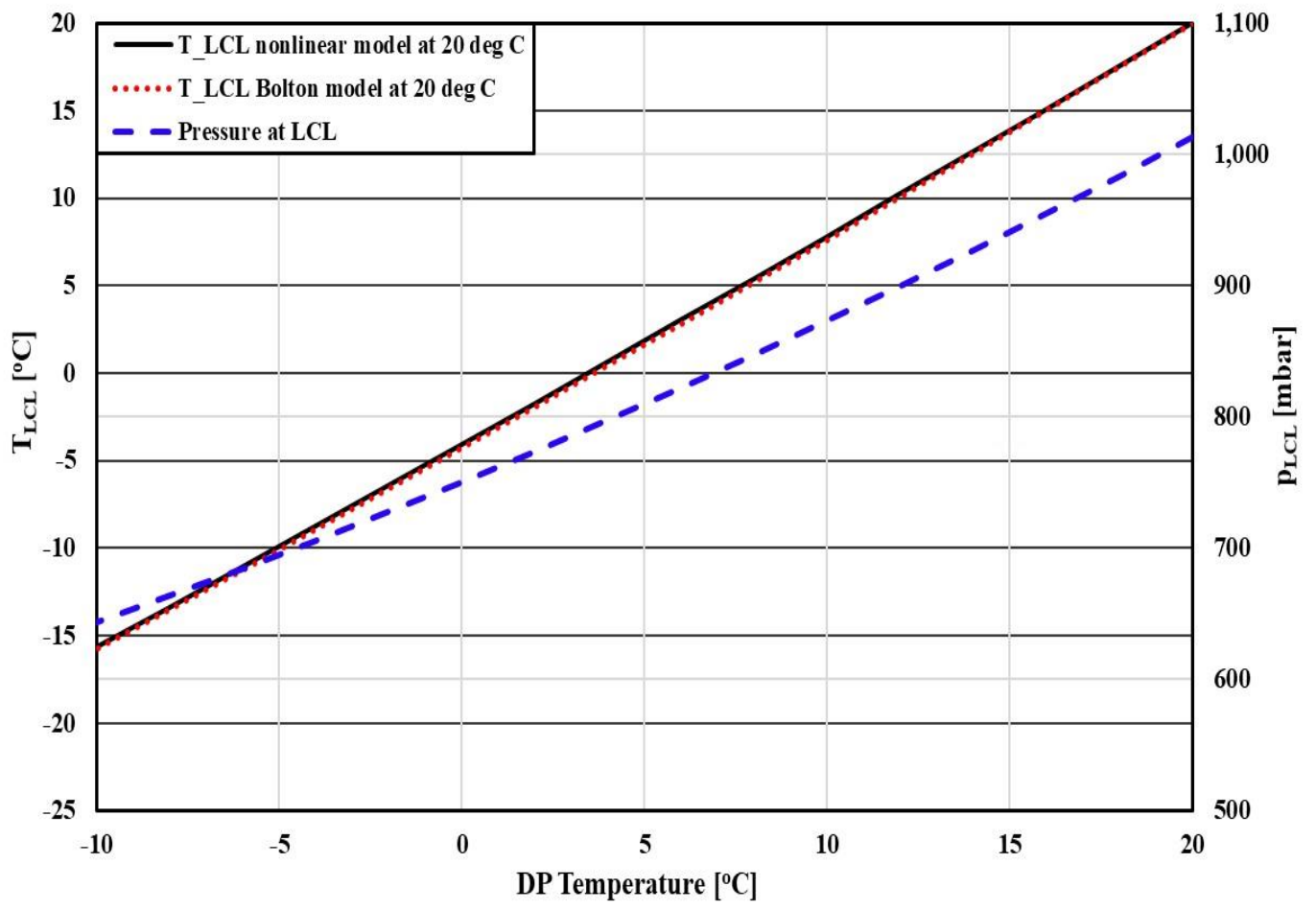

Figure 4. LCL temperature and pressure at SL ISA surface and air temperature of $20^{\circ} \mathrm{C}$.

Instead of LCL height, we could have computed LCL temperature first, such as by using successive approximations from Equation (18) and then compute LCL height and pressure. LCL height is computed from Equation (22) for known $\mathrm{T}_{\mathrm{LCL}}$. LCL temperatures and pressures using our iterative numerical solver at air temperatures of $30^{\circ} \mathrm{C}, 20^{\circ} \mathrm{C}$, and $10^{\circ} \mathrm{C}$ as a function of DP temperatures are shown in Figures. 3, 4, and 5 respectively. Comparison of Bolton's approximation and nonlinear model for $\mathrm{T}_{\mathrm{LCL}}$ developed here is shown. In general, the following relationship between various temperatures exist $\mathrm{T}_{\mathrm{LCL}}<\mathrm{T}_{\mathrm{DP}}<\mathrm{T}_{\mathrm{WB}}<\mathrm{T}<\mathrm{T}_{\mathrm{V}}$ (Daidzic, 2019a, 2019b; Dutton, 2002; Iribarne \& Godson, 1981; Stull, 2016; Tsonis, 2007). 
Bolton's approximation is plotted in the same figures. We found that the absolute deviations using Bolton's (red dotted lines) equation (Equation 21) is less than $0.4^{\circ} \mathrm{C}$ compared to our solutions (black solid lines) given by iterative procedure in Equation (18). It is often very difficult to visually resolve small differences in presented results. As the air temperature decreases, so does the absolute error using Bolton's approximation in the temperature range used. Although, appearing linear, the lines do have small curvatures to it. Atmospheric pressures at LCL are computed using Equation (20).

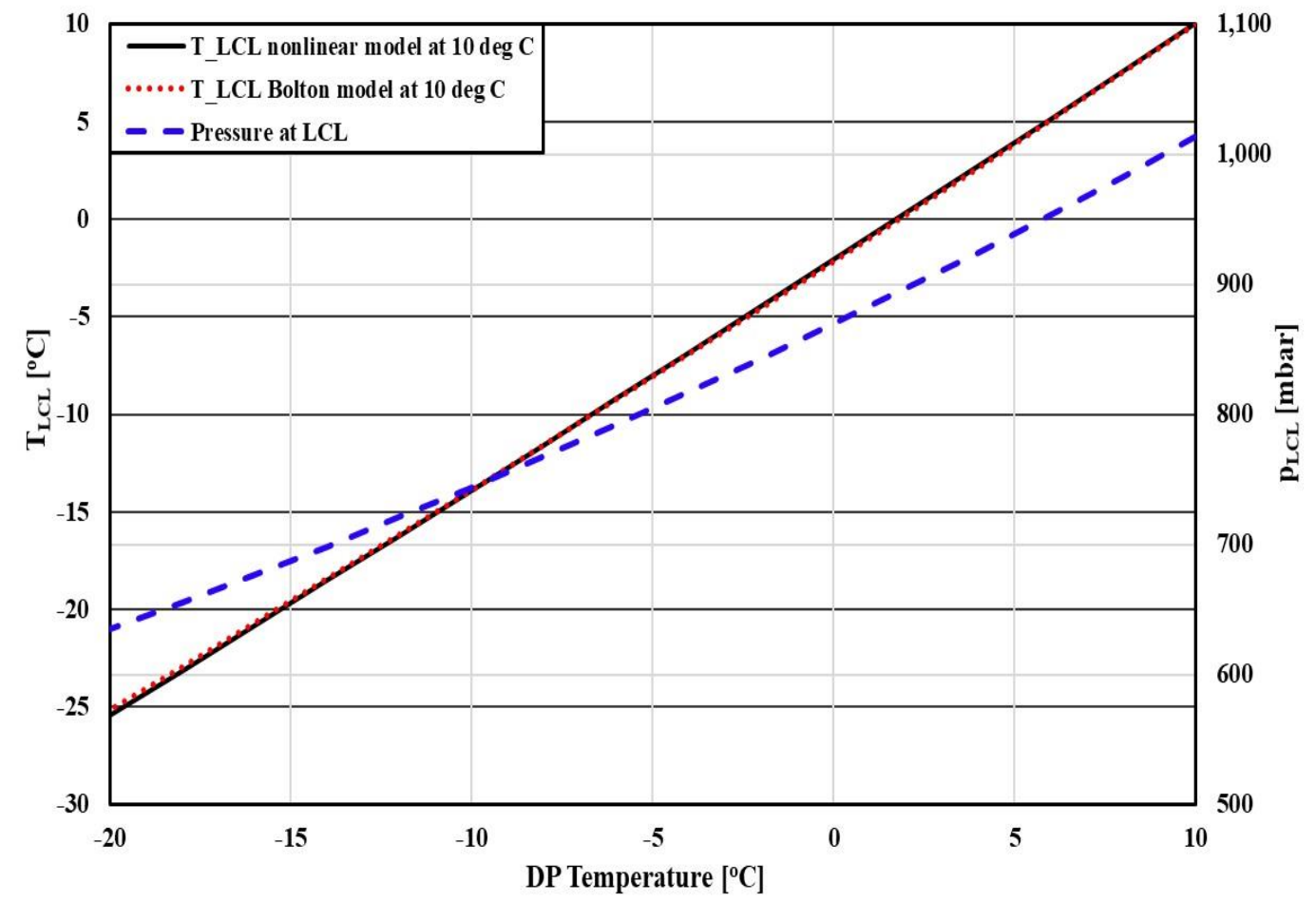

Figure 5. LCL temperature and pressure at SL ISA surface and air temperature of $10^{\circ} \mathrm{C}$.

\section{Conclusions}

In this research article, we presented a new mathematical model of lifting condensation level dynamics. The computational results are compared to other commonly-used LCL models. We estimate the LCL height, temperature, and pressure, which control the bases of the cumulus clouds formations. In fact, two different methodologies are present - one that numerically solves nonlinear implicit equation in LCL temperature and the other that first solves explicit equation in LCL 
height and then computes LCL temperature using MALR. Both approaches are based on the theoretical Clausius-Clapeyron equation for water vapor-liquid phase transition where water vapor is regarded as an ideal gas. Our model predictions are more accurate and physically more realistic than the predictions by Espy and formulas used commonly by the FAA and others in aviation education. Model developed here also includes the effect of specific humidity and atmospheric/barometric pressure. Our model predictions also compare well with the Bolton's (1980) model and come close to the results of recently derived exact LCL solution of Romps (2017). More efforts are required to understand discrepancies from Romps' model. No comparison with the experimentally collected atmospheric and weather data was performed at this point, but that could be conducted in a future investigation.

\section{Author Bio}

Dr. Nihad E. Daidzic is president and chief engineer of AAR Aerospace Consulting, L.L.C. He is also a full professor of Aviation, adjunct professor of Mechanical Engineering, and research graduate faculty at Minnesota State University. His Ph.D. (Dr.-Ing.) is in fluid mechanics and Sc.D. in mechanical engineering. He was formerly a staff scientist at the National Center for Microgravity Research and the National Center for Space Exploration and Research at NASA Glenn Research Center in Cleveland, $\mathrm{OH}$. He also held various faculty appointments at Vanderbilt University, University of Kansas, and Kent State University. His current research interest is in theoretical, experimental, and computational fluid dynamics, microand nano-fluidics, aircraft stability, control, and performance, mechanics of flight, piloting techniques, and aerospace propulsion. Dr. Daidzic is an ATP AMEL and an FAA "Gold Seal" CFI-A/CFI-IA/MEI/CFI-RH/CFI-G/AGI/IGI instructor with flight experience in airplanes, helicopters, and gliders. 


\section{Nomenclature}

\section{Greek}

$\gamma[-]$

$\varphi[-]$

$\rho\left[\mathrm{kg} / \mathrm{m}^{3}\right]$

$\Gamma[\mathrm{K} / \mathrm{m}]$

\section{Alphabetic}

$c[\mathrm{~kJ} / \mathrm{kg} \mathrm{K}]$

$e[\mathrm{~Pa}]$

$g\left[\mathrm{~m} / \mathrm{s}^{2}\right]$

$l[\mathrm{~J} / \mathrm{kg}]$

$p[\mathrm{~Pa}]$

$\mathrm{q}[-]$

$r[-]$

$z[\mathrm{~m}]$

$D[\mathrm{~K}]$

$H[\mathrm{~m}]$

$R[\mathrm{~J} / \mathrm{kg} \mathrm{K}]$

$T[\mathrm{~K}]$

\section{Subscripts}

$\begin{array}{ll}d & \text { Dry. } \\ m & \text { Mixture. } \\ p & \text { Constant pressure process. } \\ s & \text { Saturated. } \\ v & \text { Vapor, wet. }\end{array}$

Mixture ratio.
Isentropic coefficient.

Relative humidity.

Density (mass).

Lapse rate.

Specific heat capacity.

Water vapor pressure.

Terrestrial gravitational acceleration.

Mass specific latent heat (vaporization, fusion, etc.).

Pressure (thermodynamic).

Specific humidity.

Height (Orthometric).

Dew point depression (spread).

Height (Geopotential).

Gas constant (gas specific).

Temperature. 
$D P$

$L C L$

$M$

$W B$

Abbreviations

CN

$\mathrm{D}$

DB

DALR

DP

DPLR

LCL

LDL

LFL

LR

MALR

RH
Dew point.

Lifting Condensation Level.

Moist (humid).

Wet Bulb.

Condensation nuclei.

Dew point depression (spread).

Dry Bulb

Dry Adiabatic (Air) Lapse Rate.

Dew Point [K].

Dew Point Lapse Rate.

Lifting Condensation Level.

Lifting Deposition Level.

Lifting Freezing Level.

Lapse Rate $[\mathrm{K} / \mathrm{m}]$.

(unsaturated) Moist Air Adiabatic Lapse Rate.

Relative humidity. 


\section{References}

Bolton, D. (1980). The computation of equivalent potential temperature. Monthly Weather Review, 108, 1046-1053. doi:10.1175/1520-0493(1980)108, 1046:TCOEPT.2.0.CO;2

Bradbury, T. (2000). Meteorology and flight: A pilot's guide to weather (3rd ed.). London, UK: A \& C Black.

Chapra, S. C., \& Canale, R. P. (2006). Numerical methods for engineers (5th ed.). Boston, MA: McGraw-Hill.

Corless, R. M., Gonnet, G. H., Hare, D. E. G., Jeffrey, D. J., \& Knuth, D. E. (1996). On the Lambert W function. Advances in Computational Mathematics, 5(4), 329-359. doi:10.1007/bf02124750

Cosgrove, B. (1999). Pilot's weather: A commonsense approach to meteorology. Vergennes, VT: Plymouth Press.

Daidzic, N. E. (2019a). On moist air and dew points. International Journal of Aviation Aeronautics and Aerospace, 6(3), 1-36. doi:10.15394/ijaaa.2019.1339

Daidzic, N. E. (2019b). On atmospheric lapse rates. International Journal of Aviation Aeronautics and Aerospace, 6(4), 1-20. doi:10.15394/ijaaa.2019.1374

Dutton, J. A. (2002). The ceaseless wind: An introduction to the theory of atmospheric motion. Mineola, NY: Dover.

Espy, J. P. (1836). Essays on meteorology. No. IV: North-East storms, volcanoes, and columnar clouds. The Journal of the Franklin Institute, 22, 239-246, doi:10.1016/S0016-0032(36)91215-2

Federal Aviation Administration (2016). Aviation weather (AC 00-6B). Department of Transportation (DOT), Washington, DC: Author.

Iribarne, J. V., \& Cho, H.-R. (1980). Atmospheric physics. Dordrecht, Holland: D. Reidel Publishing Company.

Iribarne, J. V., \& Godson, W. L. (1981). Atmospheric thermodynamics (2nd ed.). Dordrecht, Holland: D. Reidel Publishing Company.

Jeppesen. (2015). Guided flight discovery: Instrument Commercial. Englewood, CO: Author.

Lawrence, M. G. (2005). The relationship between relative humidity and the dewpoint temperature in moist air: A simple conversion and applications. Bulletin of the American Meteorological Society, 86, 225-233. doi:10.1175/BAMS-86-2-225

Lester, P. (2007). Aviation weather (3rd ed.). Englewood, CO: JeppesenSanderson. 
McDonald, J. H. (1963). James Espy and the beginnings of cloud thermodynamics. Bulletin of the American Meteorological Society., 44, 634-641. doi:10.1175/1520-0477-44.10.634

Piggot, D. (1996). Understanding flying weather (2nd ed.). London, UK: A \& C Black.

Reichmann, H. (1993). Cross-country soaring (7th ed.). Translated from German original: Streckensegelflug. Stuttgart, Germany: Motorbuchverlag (English translation by the Soaring Society of America (SSA).

Rogers, R. R. (1979). A short course in cloud physics (2nd ed.). Oxford, UK: Pergamon Press.

Romps, D. M. (2017). Exact expression for the Lifting Condensation Level. Journal of Atmospheric Science, 74, 3891-3900. doi:10.1175/JAS-D-170102.1

Saucier, W. J. (1989). Principles of meteorological analysis. Mineola, NY: Dover.

Stull, R. (2016). Practical meteorology: An algebra-based survey of atmospheric science. Retrieved from http://www.eos.ubc.ca/books/ Practical_Meteorology/

Tsonis, A. A. (2007). An introduction to atmospheric thermodynamics (2nd ed.). Cambridge, UK: University Press.

Wallace, J. M., \& Hobbs, P. V. (2006). Atmospheric science: An introductory survey (2nd ed.). Burlington, MA: Academic Press.

Wetzel, P. J. (1990). A simple parcel method for prediction of cumulus onset and area-averaged cloud amount over heterogeneous land surfaces. Journal of Applied Meteorology, 29, 516-523. doi:10.1175/15200450(1990)029,0516:ASPMFP.2.0.CO;2

Zwillinger, D. (ed.) (2018). CRC standard mathematical tables and formulas (33rd ed.). Boca Raton, FL: CRC Press. 